\title{
Empirical Research on the Relationship between Economic Growth and Environmental Pollution in Jiangsu Province
}

\author{
Geng Chengxuan \\ College of Economics and Management, \\ Nanjing University of Aeronautics and Astronautics, Nanjing, China \\ Email: gcxuan@aliyun.com
}

\section{Doi:10.5901/mjss.2013.v4n9p322}

\begin{abstract}
On the basis of summarizing the status of the Environmental Kuznets Curve (EKC) home and abroad, this paper analyzes the relationship between Jiangsu Province's industrial three wastes indicators and establishes the optimal model environmental indicators according to the situation of the economic and environmental changes in Jiangsu Province from 1995 to 2010. Through research, the following conclusions come up: (1) The per capita GDP and the integrated level of environmental pollution EKC in Jiangsu Province is N-shaped with only one turning point; (2) The per capita GDP and the industrial wastewater emissions EKC in Jiangsu Province is N-shaped with two turning points; (3) Jiangsu Province's overall trend of the industrial waste gas emissions is quite similar with the industrial solid waste emissions, but its EKC is still within the rising phase.
\end{abstract}

Keywords: Jiangsu Province, economic growth, environmental pollution, Environmental Kuznets Curve

\section{Introduction}

In recent years, environmental issue has become one of the main constraints of Jiangsu Province's economic development. In order to achieve sustainable economic development, we can't ignore environmental factors. In the process of building Green Jiangsu, improving the environment in Jiangsu Province is the unavoidable reality facing the sustainable development of Jiangsu Province with no inhibiting the normal growth of the economy. Therefore, studying the interrelationship between Jiangsu Province's economic growth and environmental pollution is imminent [1].

\section{Environmental Kuznets Curve (EKC) theory}

In 1955, the American economists and statisticians, Kuznets, put forward the Environmental Kuznets Curve in their classic paper Economic Growth and Income Inequality. In the early 1990s, Grossman and Krueger introduced this idea to the study of the relationship between environmental pollution and economic growth, finding that the inverted U-shaped relationship between environmental quality and economic growth. Since then, EKC has won a widespread concern of many economists since its birth, and many scholars prove the EKC phenomenon from the perspective of economic structure, income environment elasticity of demand, international trade and international investment, which greatly enriched people's understanding of the mechanism of EKC. Through a large number of empirical studies, we can see four types of relationships between environmental pollution indicators and economic growth indicators (per capita income): inverted U-shaped relationship, U-shaped relationship, synchronous relationship and N-shaped relationship [2].

\section{EKC simulation of Jiangsu Province's economic growth and environmental pollution}

Since the reform and opening up, Jiangsu Province has undergone a rapid economic development. From 1995 to 2010, the average annual growth of the industrial gross domestic product (GDP) was 15.01\%, and the GDP increased from 515.525 billion yuan in 1995 to 4.142548 trillion yuan in 2010; the per capita GDP increased sustained and rapidly, the average annual growth rate reached about $14.19 \%$ and the per capita GDP in Jiangsu Province grew to 52,840 yuan in 2010. From 1995 to 2010, the economy of Jiangsu Province increased steadily, and average annual contribution rates of the second and the tertiary industries were $61.09 \%$ and $34.09 \%$ [3]. From 1995 to 2010, the total industrial wastewater increased from 220184 million tons to 231014 million tons, industrial waste gas emissions increased to 3.1213 trillion 
standard cubic meters from 787.2 billion standard cubic meters, and industrial solid waste generated from the 28.83 million tons to 83.5 million tons [4].

So this paper selects Jiangsu Province's representative environmental indicators to describe Jiangsu Province's environmental pollution level: sewage wastewater emissions (million tons), industrial emissions (hundred million cubic meters) as well as generated industrial solid waste (million tons) and selects Jiangsu Province's per capita GDP over the years to present the economic growth level. We select the rapid growth period in Jiangsu Province, 1995 to 2010, as the time-series data interval of environmental pollution indicators. All the data come from the Jiangsu Statistical Yearbook (1995-2010) [5]. According to the EKC theory, scholars usually use EKC model $y=b_{0}+b_{1} X+b_{2} X^{2}+b_{3} X^{3}+\mu$, in which $y$ is an indicator of environmental pollution, and $x$ means the per capita GDP, $b_{0}, b_{1}, b_{2}$ and $b_{3}$ are model parameters, while $\mu$ is the random error [6].

\section{Model building of economic growth and environmental pollution level}

To study the relationship between economic growth and environmental pollution level, we must establish a new indicator - the comprehensive environmental pollution indicator on the basis of the industrial three wastes indicators. We first multiply the density of exhaust gas with industrial emissions $\left(\rho=1.29 \mathrm{~kg} / \mathrm{m}^{3}\right)$. Then conduct conversion to get the unit of weight ton and add the total sum, namely: the total amount of environmental pollution emissions = industrial waste water emissions + industrial waste gas emissions $x$ exhaust gas density + industrial solid waste volume [7]. By analyzing the integrated environmental pollution level and per capita GDP with the SPSS, the results are shown in Table 1 and Fig. 1.

Table 1. Simulation results of economic growth and the level of environmental pollution

Dependent Variable: Environmental Pollution level

\begin{tabular}{|c|c|c|c|c|c|c|c|c|c|}
\hline Equation & \multicolumn{4}{|c|}{ Model Summary } & \multicolumn{4}{c|}{ Parameter Estimates } \\
\hline & R Square & $\mathrm{F}$ & $\mathrm{df1}$ & $\mathrm{df} 2$ & Sig. & Constant & $\mathrm{b} 1$ & $\mathrm{~b} 2$ & b3 \\
\hline Cubic & 0.903 & 37.047 & 3 & 12 & .000 & 7755.026 & 43.985 & -0.001 & $1.06 \mathrm{E}-008$ \\
\hline
\end{tabular}

The independent variable is per capita GDP (yuan)

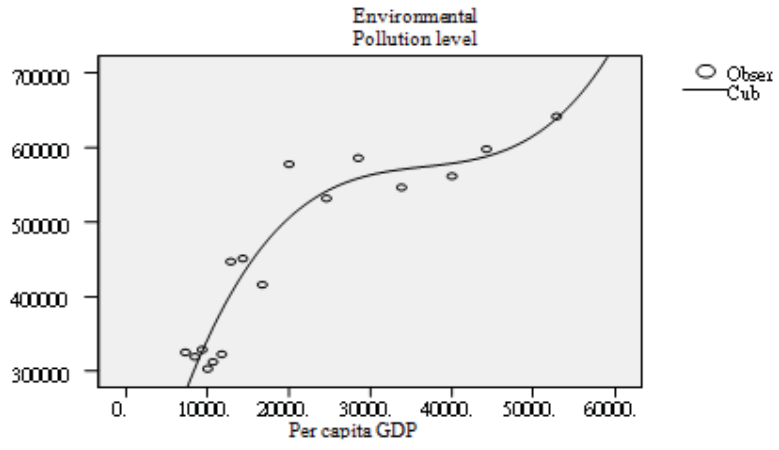

Fig.1. The fitting curve of per capita GDP and the level of environmental pollution

Table 1 shows that $b_{1}>0, b_{2}<0, b_{3}>0$. So the EKC of Jiangsu Province's per capita GDP and environmental pollution level shows the N-shaped characteristics. Fitting through the SPSS, we can find that there is an N-shaped EKC between the two. $b_{2}{ }^{2}-3 b_{1} b_{3}<0$ shows that the N-shaped curve has only one inflection point, $x^{*}=-b_{2} / 3 b_{3} \approx 31447$ means that with the growth of per capita GDP, environmental pollution emissions continue to grow. And when the curve reaches the turning point -31447 yuan, the growth rate of environmental pollution will further increase, meanwhile the N-shaped curve increased monotonically.

\section{Model building of economic growth and industrial three wastes pollution level}

Using SPSS software to analyze the relationship between economic growth and industrial wastewater emissions, we can 
get the following simulation results (Table 2) and fitting curve (Fig.2).

Table 2. Simulation results of economic growth and industrial wastewater emissions

Dependent Variable: industrial wastewater emissions (ten thousand ton)

\begin{tabular}{|c|c|c|c|c|c|c|c|c|}
\hline Equation & \multicolumn{4}{|c|}{ Model Summary } & \multicolumn{4}{c|}{ Parameter Estimates } \\
\hline & R Square & F & df1 & df2 & Sig. & b1 & b2 & b3 \\
\hline Cubic & 0.990 & 426.713 & 3 & 13 & 0.000 & 30.491 & -0.001 & $1.06 \mathrm{E}-008$ \\
\hline
\end{tabular}

The independent variable is per capital GDP (yuan)

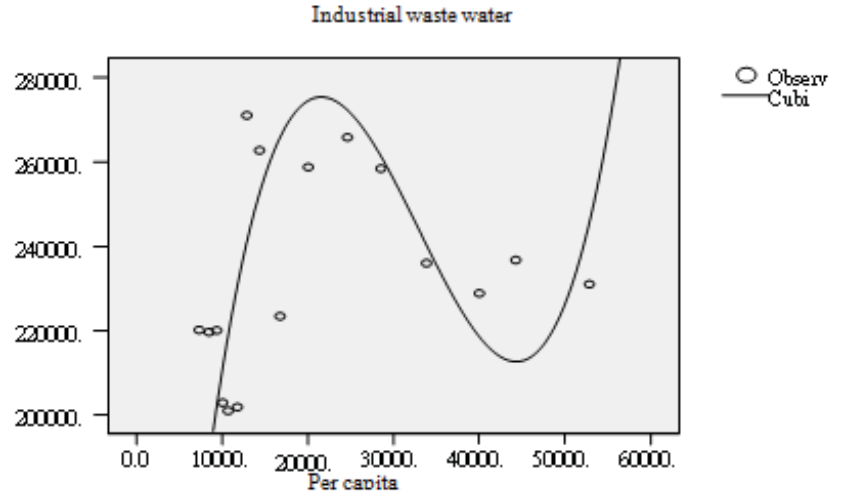

Fig.2. The fitting curve of per capita GDP and industrial wastewater emissions

According to symbols of $b_{1}, b_{2}$, $b_{3}$ in Table 2 , we can see that there is N-shaped relationship between the per capita GDP and industrial wastewater emissions. $\mathrm{b}_{2}{ }^{2}-3 \mathrm{~b}_{1} \mathrm{~b}_{3}>0$ indicates that the $\mathrm{N}$-shaped curve has two inflection points. After calculated, the income turning point turn out to be for 25,965 yuan and 36,928 yuan, that is, industrial waste water grows with the growth of per capita income. It begins to decrease after reaching the EKC turning point- 25,965 yuan. But this inverted U-shaped EKC relationship is only a temporary phenomenon, after the second turning point- 36,928 yuan in revenue growth, industrial wastewater emissions begin to grow with the increase in per capita GDP, so the whole process is an $\mathrm{N}$-shaped curve. The economic growth and industrial waste gas emissions simulation result is shown in Table 3 by using the same model. The fitting curve of per capita GDP and industrial emissions is shown in Fig. 3 .

Table 3. Simulation results of economic growth and industrial waste gas emissions

Dependent Variable: industrial waste gas emissions (ten thousand ton)

\begin{tabular}{|c|c|c|c|c|c|c|c|c|c|}
\hline Equation & \multicolumn{5}{|c|}{ Model Summary } & \multicolumn{4}{c|}{ Parameter Estimates } \\
\hline & R Square & F & df1 & df2 & Sig. & Constant & b1 & b2 & b3 \\
\hline Cubic & 0.946 & 69.728 & 3 & 12 & 0.000 & -9752.829 & 2.432 & $-6.02 \mathrm{E}-005$ & $5.46 \mathrm{E}-010$ \\
\hline
\end{tabular}

The independent variable is per capita GDP (yuan) 


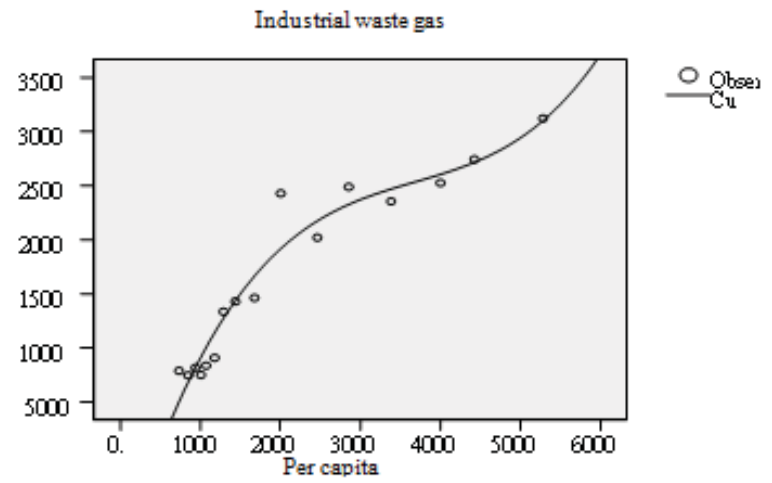

Fig.3. The fitting curve of per capita GDP and industrial waste gas emissions

The symbols of parameters $b_{1}, b_{2}, b_{3}$ show that there is an $\mathrm{N}$-shaped relationship between per capita GDP and industrial waste gas emissions. $b_{2}{ }^{2}-3 b_{1} b_{3}<0$ indicates that the $\mathrm{N}$-shaped curve has only one inflection point, at which the income is $x^{\star}=-b_{2} / 3 b_{3} \approx 36752$ yuan, and the curve increases monotonically. We can see from the actual observed data that the $\mathrm{N}$ shaped curve shows that industrial waste gas emission grows with the growth of per capita GDP, and accelerates its growth across the inflection point of 36,752 yuan. The simulation results are shown in Table 4 and fitting curve is show in Fig.4.

Table 4. Simulation results of Economic growth and industrial solid waste production

Dependent Variable: Inductrial solid waste production (ten thousand ton)

\begin{tabular}{|c|c|c|c|c|c|c|c|c|c|}
\hline Equation & \multicolumn{6}{|c|}{ Model Summary } & \multicolumn{4}{c|}{ Parameter Estimates } \\
\hline & R Square & $\mathrm{F}$ & $\mathrm{df1}$ & $\mathrm{df} 2$ & Sig. & Constant & b1 & b2 & b3 \\
\hline Cubic & .960 & 97.105 & 3 & 12 & .000 & 578.386 & .275 & $-3.29 \mathrm{E}-006$ & $1.52 \mathrm{E}-011$ \\
\hline
\end{tabular}

The independent variable is per capital GDP (yuan)

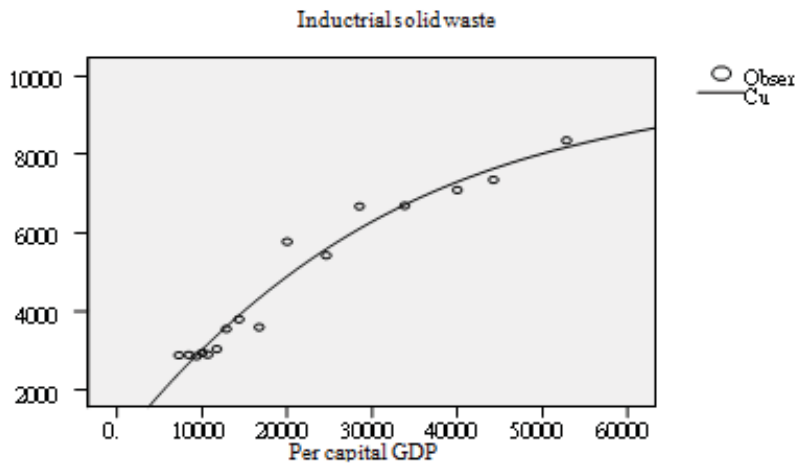

Fig.4. The fitting curve of per capita GDP and industrial solid waste production

The symbols of parameters $b_{1}, b_{2}, b_{3}$ show that there is an N-shaped relationship between per capita GDP and industrial solid waste generation. $b_{2}{ }^{2}-3 b_{1} b_{3}<0$ indicates that the $\mathrm{N}$-shaped curve has only one inflection point, at which the income is $x^{\star}=-b 2 / 3 b 3 \approx 72149$ yuan, that is, the industrial solid waste generation is monotonically increasing along with the increase in per capita GDP. At present, the per capita GDP of Jiangsu Province has not yet reached 72,149 yuan, so we have to take the opportunity to accelerate the optimization of economic structure, change the mode of economic growth in order to change the development trend of the curve before reaching the inflection point and achieve sustainable economic development [8]. 


\section{Conclusions and recommendations}

On the basis of the specific stage and the particular condition of economic development, this paper takes Jiangsu Province as example and conducts an in-depth study of the relationship between economic growth and environmental pollution. The conclusions are as follows:

1) The EKC of per capita GDP and the comprehensive level of environmental pollution is N-shaped, and there is only a turning point of 31,447 yuan, that is, environmental pollution deepens with the growth of per capita GDP;

2) There is an N-shaped relationship between per capita GDP and industrial wastewater emissions in Jiangsu Province, but there are two turning points, respectively, 25,965 yuan and 36,928 yuan;

3) ) The industrial waste gas emission of Jiangsu Province has the same tendency as industrial solid waste generation. In the short term, environmental pollution has a trend of accelerated growth. In the long term, when achieving a higher income level, pollution may be gradually improved, but it is still in the rising phase of the EKC.

A few recommendations are put forward according to the above research. (1) Transform the economic growth mode and speed up the upgrading of industrial structure. (2) Improve the environmental investment, and promote scientific and technological innovation. (3) Develop the recycling economy. [9] (4) Use economic instruments for environmental protection. (5) Improve the environmental laws and increase the environmental protection law enforcement. (6) Strengthen the environmental publicity effort and raise environmental awareness. (7) Conduct the implementation of green GDP accounting. [10]

\section{References}

The 12th Five-year Plan of Jiangsu Province. In Chinese.

Robert K, Kaufmann, Brynhildur Davidsdottir, Sophie Garnham, Peter Paulym, Ecological Economics, 1998:25(2).

Friedl B, Getzner M, Ecological Economics, 2003:45(1).

Haisheng Yang, Yongzhang Zzhou, Xizi Wang. Statistics and Decision, 2008(10), In Chinese.

Wenhua He, West Forum, 2010(3), In Chinese.

2010 Jiangsu Provinces's State of the Environment, In Chinese.

Fengzhong Cao, Guomei Zhou, Huanyun Zhou. Environmental Science and Technology, 1999(4), In Chinese.

Qian Zhou, Statistics and Information Forum, 2011(10), In Chinese.

Bo Sun, Hui Li, Harbin University of Commerce: Social Science, 2009(4), In Chinese.

Beilei Gao, Pollution Control Technology, 2009(6), In Chinese. 